\title{
EXTRAÇÃO E EXPORTAÇÃO DE NUTRIENTES EM CULTIVARES DE BATATA: II - MICRONUTRIENTES ${ }^{(1)}$
}

\author{
Rogério Peres Soratto ${ }^{(2)}$, Adalton Mazetti Fernandes ${ }^{(3)}$ \& Genivaldo \\ David de Souza-Schlick ${ }^{(3)}$
}

\begin{abstract}
RESUMO
Cultivares de batata mais produtivas possivelmente exigem maior quantidade de micronutrientes, porém no Brasil há carência de informações sobre extração e exportação de micronutrientes pelas principais cultivares de batata utilizadas. $O$ objetivo deste trabalho foi avaliar a produtividade de tubérculos, a extração e a exportação de micronutrientes nas cultivares de batata Ágata, Asterix, Atlantic, Markies e Mondial. $O$ experimento foi conduzido durante a safra de inverno, em um Latossolo Vermelho, no município de Itaí (SP). As parcelas foram constituídas pelas cinco cultivares, e as subparcelas, por épocas de coletas, realizadas no momento do plantio e a cada sete dias após a emergência. As cultivares Mondial e Asterix, mais produtivas, apresentaram maior extração de micronutrientes, com quantidades médias por hectare de $71 \mathrm{~g}$ de $\mathrm{B}, 122 \mathrm{~g}$ de $\mathrm{Cu}, 2.228 \mathrm{~g}$ de $\mathrm{Fe}, 618 \mathrm{~g}$ de Mn e $405 \mathrm{~g}$ de Zn. As menores quantidades extraídas foram observadas na cultivar Atlantic, com valores de 50, 81, 1.960, 544 e $270 \mathrm{~g} \mathrm{ha}^{-1} \mathrm{de} \mathrm{B,} \mathrm{Cu,} \mathrm{Fe,} \mathrm{Mn} \mathrm{e} \mathrm{Zn,}$ respectivamente. A fase de maior demanda por $B$ ocorre logo após o início da formação de tubérculos, aos $34 \mathrm{DAP}$, enquanto a maior demanda por $\mathrm{Fe}$ e $\mathrm{Mn}$ inicia-se a partir dos 42 DAP e vai até 63 DAP. O Cu e o $\mathrm{Zn}$ são absorvidos em maiores proporções a partir dos 64 DAP até o final do ciclo. A quantidade de B, Cu, Mn e Zn exportada foi dependente da cultivar, com valores por hectare variando de 48 a 22 g de B, 79 a 16 g de Cu, 65 a 37 g de Mn e 167 a 83 g de Zn. A quantidade de Fe exportada não variou entre as cultivares, sendo, em média, de $243 \mathrm{~g} \mathrm{ha}^{-1}$. A
\end{abstract}

\footnotetext{
(1) Parte da Dissertação de Mestrado do segundo autor apresentada à Faculdade de Ciências Agronômicas, Universidade Estadual Paulista - FCA/UNESP. Recebido para publicação em 18 de agosto de 2010 e aprovado em 1 de setembro de 2011.

(2) Professor Adjunto do Departamento de Produção Vegetal, Faculdade de Ciências Agronômicas, Universidade Estadual Paulista - FCA/UnESP. Campus de Botucatu, Caixa Postal 237, CEP 18603-970 Botucatu (SP). Bolsista do CNPq. E-mail: soratto@fca.unesp.br

(3) Doutorando em Agronomia (Agricultura), FCA/UNESP. E-mails: adalton@fca.unesp.br; genivald@fca.unesp.br
} 
quantidade de micronutrientes extraída e exportada pela batateira variou com as cultivares utilizadas, indicando necessidade de manejo diferencial da adubação.

Termos de indexação: Solanum tuberosum, nutrição mineral, curvas de absorção, taxas de absorção, acúmulo de nutrientes.

\title{
SUMMARY: NUTRIENT EXTRACTION AND EXPORTATION BY POTATO CULTIVARS: II - MICRONUTRIENTS
}

\begin{abstract}
More productive potato cultivars possibly require larger quantities of micronutrients, but in Brazil there is little information on extraction and exportation of micronutrients by the commonly used potato cultivars. The objective of this study was to evaluate extraction and exportation of micronutrients by the potato cultivars Ágata, Asterix, Atlantic, Markies, and Mondial. The experiment was conducted in Itai, São Paulo State, Brazil, in the 2008 winter growing season on an Oxisol. Plots consisted of the five potato cultivars and subplots of sampling times (at planting and every seven days after emergence). The cultivars Mondial and Asterix, the most productive, absorbed highest average micronutrient quantities per hectare (71 $\mathrm{g} \mathrm{B}, 122 \mathrm{~g} \mathrm{Cu}, 2,228 \mathrm{~g} \mathrm{Fe}, 618 \mathrm{~g} \mathrm{Mn}$, and $405 \mathrm{~g} \mathrm{Zn).} \mathrm{Smaller} \mathrm{average} \mathrm{amounts} \mathrm{were}$ absorbed by Atlantic (50, 81, 1,960, 544, and $270 \mathrm{~g} \mathrm{ha} \mathrm{a}^{-1}$ of $\mathrm{B}, \mathrm{Cu}, \mathrm{Fe}, \mathrm{Mn}$, and $\mathrm{Zn}$, respectively). $B$ demand was highest after tuber initiation, 34 days after planting (DAP), while the Fe and $M n$ demand was highest between 42 DAP and 63 DAP. Cu and Zn were most absorbed from $64 \mathrm{DAP}$ until the end of the cycle. The exported amounts of $\mathrm{B}, \mathrm{Cu}, \mathrm{Mn}$, and $\mathrm{Zn}$ were cultivardependent, in the ranges 48-22 g B, 79-16 g Cu, 65-37 $\mathrm{g} \mathrm{Mn}$, and 167-83 $\mathrm{g} \mathrm{ha}^{-1} \mathrm{Zn}$. Average Fe exportation did not differ among cultivars $\left(243 g \mathrm{ha}^{-1}\right)$. The micronutrient quantities absorbed and exported by potato cultivars varied between cultivars, indicating the need of a differentiated fertilization management.
\end{abstract}

Index terms: Solanum tuberosum, mineral nutrition, absorption curves, absorption rates, nutrient accumulation.

\section{INTRODUÇÃO}

Normalmente, no cultivo da batata (Solanum tuberosum L.) são utilizadas altas doses de fertilizantes com N, P e K (Cogo et al., 2006; Silva et al., 2007), por ser esta uma cultura altamente responsiva ao suprimento de nutrientes (Cardoso et al., 2007). No entanto, muitas vezes os micronutrientes não são incluídos nos programas de adubação da cultura, podendo ocorrer situações de "fome oculta", em que sintomas visíveis de deficiência não são constatados, porém a insuficiência de micronutrientes limita a produtividade (Raij, 2001) e a qualidade do produto colhido (Mesquita Filho et al., 2001). Embora os micronutrientes sejam absorvidos em pequenas quantidades, eles são tão importantes quanto os macronutrientes, desempenhando funções como ativador ou constituinte de enzimas, além do papel estrutural, como constituinte de compostos orgânicos (Malavolta et al., 1997; Dechen \& Nachtigall, 2006).

Segundo Boock (1976) e Filgueira (1993), a carência de micronutrientes em batata está associada ao uso de fertilizantes com maior grau de pureza, à exportação dos micronutrientes do solo por plantios consecutivos em uma mesma área, ao uso de cultivares com maior potencial produtivo, bem como à aplicação de elevadas doses de macronutrientes. Mesmo assim, ainda há carência de informações sobre extração e exportação de micronutrientes na cultura da batata.

No Estado de São Paulo, a recomendação de adubação com micronutrientes inclui apenas o B (Lorenzi et al., 1997), devido ao fato de ter sido constatado que a adição desse micronutriente no solo aumenta a produção de tubérculos graúdos (Gargantini et al., 1970; Boock, 1976; Freire et al., 1981) e diminui os teores de açúcares redutores (Mesquita et al., 2007), melhorando assim a produtividade e a qualidade dos tubérculos. Estudos de adubação com os demais micronutrientes foram conduzidos nas condições brasileiras, no entanto, aumentos expressivos de produtividade foram obtidos apenas com a aplicação de B e Mo (Gargantini et al., 1970, 1986). A falta de resposta na produtividade da cultura fez com que a maioria dos micronutrientes não fosse incluída nas recomendações oficiais de adubação, fato que pode causar desequilíbrio nutricional da planta e comprometer a produtividade de tubérculos. Além disso, a maioria dos estudos com micronutrientes é das décadas de 1970 e 1980 (Gargantini et al., 1970; Boock, 1976; Freire et al., 1981; Gargantini et al., 1986; Paula et al., 1986), com cultivares antigas e de menor potencial produtivo. 
Os níveis de produtividade alcançados pela cultura da batata no Brasil praticamente dobraram nos últimos anos, passando de 10 a $15 \mathrm{t} \mathrm{ha}^{-1}$ na década de 1980 para 25 a 30 t ha $^{-1}$ atualmente (Faostat, 2011), com áreas que chegam a produzir acima de $40 \mathrm{tha}^{-1}$. Esse aumento de produtividade deveu-se a inúmeros fatores, mas principalmente ao uso de cultivares mais produtivas, como Agata, Asterix, Atlantic, Markies e Mondial, que representam $78 \%$ da área cultivada com batata no Brasil (Abba, 2010). Dessa forma, como as produtividades obtidas são maiores, possivelmente as necessidades nutricionais também foram alteradas, tornando necessário conhecer as curvas de absorção de micronutrientes dessas cultivares. Com essas curvas, é possível definir as épocas em que são demandadas as maiores quantidades de micronutrientes (Orlando Filho, 2001), assim como as quantidades que são removidas da área de cultivo pelos tubérculos. Essas informações permitirão manejar de forma eficiente as adubações, visando reduzir perdas e aumentar o aproveitamento dos nutrientes dos adubos, além de auxiliar no estabelecimento de adubações de restituição, para manutenção da fertilidade do solo.

O objetivo deste trabalho foi avaliar a extração e a exportação de micronutrientes (B, $\mathrm{Cu}, \mathrm{Fe}, \mathrm{Mn}$ e $\mathrm{Zn}$ ) pelas cultivares de batata Ágata, Asterix, Atlantic, Markies e Mondial.

\section{MATERIAL E MÉTODOS}

O experimento foi conduzido durante a safra de inverno de 2008, em área produtora de batata no município de Itaí (SP) $\left(23^{\circ} 28^{\prime} \mathrm{S}, 49^{\circ} 08^{\prime} \mathrm{W}\right.$ e $670 \mathrm{~m}$ de altitude). O clima da região é $\mathrm{Cfa}$, segundo a classificação de Köppen. Os valores de temperaturas máximas e mínimas, precipitação pluvial e irrigação durante o período de condução do experimento estão apresentados na figura 1 . As características químicas da camada arável (0-0,20 m) do Latossolo Vermelho, textura argilosa (Embrapa, 2006), foram determinadas antes da instalação do experimento, segundo métodos propostos por Raij et al. (2001), cujos resultados foram: matéria orgânica, $31,8 \mathrm{~g} \mathrm{dm}^{-3}$; $\mathrm{pH}\left(0,01 \mathrm{~mol} \mathrm{~L}^{-1}\right.$ $\mathrm{CaCl}_{2}$ ), 4,4; $\mathrm{P}$ (resina), $71 \mathrm{mg} \mathrm{dm}{ }^{-3} ; \mathrm{K}, \mathrm{Ca}^{2+}, \mathrm{Mg}^{2+}$, $\mathrm{H}+\mathrm{Al}$ e CTC, 5,6, 28,6, 6,1, 74,7 e 115,1 $\mathrm{mmol}_{\mathrm{c}} \mathrm{dm}^{-3}$, respectivamente; saturação por bases, $35 \%$; e teores de $\mathrm{S}_{-} \mathrm{SO}_{4}{ }^{2-}, \mathrm{B}, \mathrm{Cu}, \mathrm{Fe}, \mathrm{Mn}$ e $\mathrm{Zn}$, respectivamente de $23,1,2,1,1,7,32,2,17,1$ e $3,1 \mathrm{mg} \mathrm{dm}^{-3}$.

O delineamento experimental foi em blocos casualizados, em esquema de parcela subdividida, com quatro repetições. As parcelas foram constituídas por cinco cultivares de batata (Ágata, Asterix, Atlantic, Markies e Mondial), e as subparcelas, por épocas de coletas de plantas (avaliações), que foram realizadas no momento do plantio (tubérculos-semente) e aos 20, $27,34,41,48,55,62,69,76,83,90$ e 97 dias após o plantio (DAP). Cada parcela foi constituída por 10 fileiras de $10 \mathrm{~m}$ de comprimento.

O preparo do solo foi realizado com: dessecação, roçagem, duas gradagens pesadas, escarificação, aração e uma terceira gradagem leve às vésperas do plantio. A adubação de plantio foi a utilizada pelo produtor, a qual constou da aplicação de $2.100 \mathrm{~kg} \mathrm{ha}^{-1}$ da fórmula N-P-K 04-30-10, no sulco de plantio, com o auxílio de um sulcador-adubador mecanizado. Não foi realizada adubação com $\mathrm{S}$ e micronutrientes, pois os teores no solo já se encontravam altos, de acordo com Raij et al. (1997). Após a adubação, os sulcos foram abertos mecanicamente, e o plantio foi realizado manualmente, no dia $8 / 6 / 2008$, no espaçamento de $0,80 \mathrm{~m}$ entre fileiras e $0,35 \mathrm{~m}$ entre plantas. Utilizaram-se tubérculos-semente certificados, tipo III, com massa média de 41, 48, 36, 28 e 31 g, respectivamente, para as cultivares Ágata, Asterix, Atlantic, Markies e Mondial.

Foram aplicados $227 \mathrm{~kg} \mathrm{ha}^{-1}$ da fórmula N-P-K 2005-20 em cobertura, aos 29 DAP, antecedendo a amontoa. A irrigação e o manejo fitossanitário da

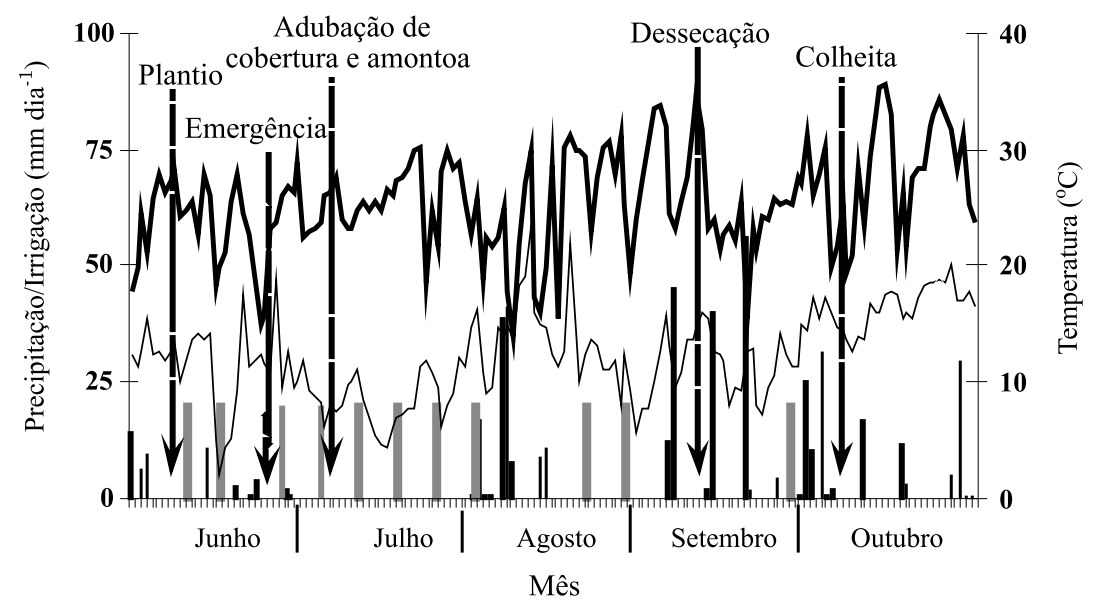

Figura 1. Precipitação pluvial ( | ), irrigação ( | ), temperaturas máximas (_) e mínimas (_) registradas na área do experimento, durante o período de junho a outubro de 2008. 
cultura seguiram as recomendações técnicas para a cultura e os critérios adotados pelo produtor.

Em cada época de coleta, ou seja, nos dias 28/6, 5/ $7,12 / 7,19 / 7,26 / 7,2 / 8,9 / 8,16 / 8,23 / 8,30 / 8,6 / 9$ e $13 /$ 9/2008, foram retiradas de cada parcela quatro plantas inteiras que tinham de todos os lados plantas competitivas e que se apresentavam aparentemente bem nutridas e com ausência de sintomas de viroses. As plantas amostradas foram separadas em tubérculos-semente, raízes, hastes, folhas, tubérculos, lavadas e secas em estufa de circulação forçada de ar à $65^{\circ} \mathrm{C}$ por $96 \mathrm{~h}$ e pesadas. Os dados de matéria seca (MS) associados às épocas de coleta de plantas foram usados para obtenção das curvas de acúmulo de MS (Fernandes et al., 2010).

Em cada data de coleta foi definido o estádio de desenvolvimento das plantas de cada cultivar, sendo considerado como: estádio I - crescimento vegetativo, da emergência até 34 DAP; estádio II - tuberização, de 35 a 41 DAP; estádio III - enchimento de tubérculos, de 42 a 90 DAP; e estádio IV - maturação, de 91 a 122 DAP.

As amostras foram moídas em moinho tipo Wiley e determinaram-se os teores de micronutrientes (B, $\mathrm{Cu}, \mathrm{Fe}, \mathrm{Mn}$ e $\mathrm{Zn}$ ), segundo método descrito por Malavolta et al. (1997). Com os dados de teor dos micronutrientes e acúmulo de MS, calculou-se a quantidade de micronutrientes acumulada em cada parte da planta e na planta inteira. As taxas de acúmulo dos micronutrientes na planta inteira e nos tubérculos foram obtidas por meio da derivada primeira da equação ajustada da quantidade acumulada desses nutrientes na planta e nos tubérculos, respectivamente. As taxas diárias máximas de acúmulo dos micronutrientes na planta inteira e nos tubérculos foram consideradas como sendo o valor médio entre 90 e $100 \%$ do valor máximo das taxas (Greef et al., 1999). O período até a taxa máxima de acúmulo dos micronutrientes foi definido como o número de dias do plantio até atingir $90 \%$ do valor máximo das taxas de acúmulo (Greef et al., 1999). A duração da taxa máxima foi definida como o período no qual a taxa de acúmulo dos micronutrientes permaneceu superior a 90 \% do valor máximo (Greef et al., 1999).

Aos 30 dias após a emergência (DAE) (48 DAP), foi feita a amostragem de folhas (terceira folha a partir do tufo apical) em cada unidade experimental, de acordo com Lorenzi et al. (1997), para determinação da diagnose do estado nutricional dos micronutrientes (B, Cu, Fe, Mn e Zn) nas plantas. As análises do tecido vegetal foram realizadas segundo método proposto por Malavolta et al. (1997).

Aos 97 DAP, realizou-se a dessecação da parte aérea das plantas de todas as cultivares com o herbicida diquat (330 g do i.a. ha ${ }^{-1}$ ), e aos 122 DAP os tubérculos de 20 plantas das linhas centrais de cada parcela foram colhidos para determinação da produtividade. A exportação de micronutrientes foi obtida a partir dos dados de acúmulo de MS (Fernandes et al., 2010) e teor dos micronutrientes nos tubérculos colhidos aos 122 DAP.

Os dados obtidos foram submetidos à análise de variância. As médias das cultivares foram comparadas pelo teste de Tukey a $5 \%$. Os efeitos das épocas de coletas de plantas foram avaliados mediante análise de regressão, com auxílio do software SigmaPlot 10.0 .

\section{RESULTADOS E DISCUSSÃO}

A cultivar Mondial apresentou teor de B na folhadiagnose (64 $\mathrm{mg} \mathrm{kg}^{-1}$ ) maior que o das cultivares Atlantic (41 $\mathrm{mg} \mathrm{kg}^{-1}$ ) e Markies (43 $\mathrm{mg} \mathrm{kg}^{-1}$ ), porém sem diferir das demais (Quadro 1). O teor foliar de B observado nas cultivares Mondial, Ágata e Asterix foi superior ao relatado como adequado (25 a $50 \mathrm{mg} \mathrm{kg}^{-1}$ ) por Lorenzi et al. (1997), provavelmente devido à alta disponibilidade de B no solo. Das cultivares estudadas, somente Atlantic e Markies se enquadraram na faixa proposta como adequada por Jones Junior (1991) e Lorenzi et al. (1997). Mesquita et al. (2008) observaram que em solos com baixa disponibilidade de $\mathrm{B}\left(0,3\right.$ e $\left.0,4 \mathrm{mg} \mathrm{dm}^{-3}\right)$, em que não foi feita adubação boratada, o teor foliar desse nutriente nas cultivares Asterix e Monalisa ficou entre 25 e $30 \mathrm{mg} \mathrm{kg}^{-1}$, ou seja, inferior ao obtido no presente estudo.

No que se refere ao $\mathrm{Cu}$, a cultivar Asterix apresentou o maior teor foliar (55 $\mathrm{mg} \mathrm{kg}^{-1}$ ), superior ao obtido nas cultivares Atlantic, Markies e Mondial (Quadro 1). No entanto, todas as cultivares obtiveram teor foliar de $\mathrm{Cu}$ superior ao intervalo proposto como adequado por Jones Junior (1991) e Lorenzi et al. (1997), que é de 7 a $20 \mathrm{mg} \mathrm{kg}^{-1}$. Não houve diferença entre as cultivares quanto ao teor foliar de Fe, Mn e Zn (Quadro 1). No entanto, todas elas apresentaram teor foliar acima da faixa descrita como adequada por Jones Junior (1991) e Lorenzi et al. (1997) para os micronutrientes Fe e Mn, a qual é de 50 a $100 \mathrm{mg} \mathrm{kg}^{-1}$ de Fe e 30 a $250 \mathrm{mg} \mathrm{kg}^{-1}$ de $\mathrm{Mn}$. O teor foliar de $\mathrm{Zn}$

Quadro 1. Teor de B, Cu, Fe, Mn e Zn na folha de cultivares de batata

\begin{tabular}{llllll}
\hline Cultivar & B & Cu & Fe & Mn & Zn \\
& & & & \\
& & & & \\
& & & & \\
Ágata & $54 \mathrm{ab}$ & $41 \mathrm{ab}$ & $520 \mathrm{a}$ & $449 \mathrm{a}$ & $76 \mathrm{a}$ \\
\cline { 2 - 5 } Asterix & $59 \mathrm{ab}$ & $55 \mathrm{a}$ & $430 \mathrm{a}$ & $436 \mathrm{a}$ & $73 \mathrm{a}$ \\
Atlantic & $41 \mathrm{~b}$ & $31 \mathrm{~b}$ & $385 \mathrm{a}$ & $453 \mathrm{a}$ & $63 \mathrm{a}$ \\
Markies & $43 \mathrm{~b}$ & $30 \mathrm{~b}$ & $431 \mathrm{a}$ & $435 \mathrm{a}$ & $66 \mathrm{a}$ \\
Mondial & $65 \mathrm{a}$ & $27 \mathrm{~b}$ & $432 \mathrm{a}$ & $351 \mathrm{a}$ & $83 \mathrm{a}$ \\
CV (\%) & 18,4 & 26,7 & 32,3 & 11,3 & 13,1
\end{tabular}

Médias seguidas de mesma letra, nas colunas, não diferem entre si pelo teste de Tukey a $5 \%$. 
observado em todas as cultivares enquadrou-se dentro do intervalo considerado adequado por Jones Junior (1991), que é de 45 a $250 \mathrm{mg} \mathrm{kg}^{-1}$. O fato de todos os micronutrientes catiônicos ( $\mathrm{Cu}, \mathrm{Fe}, \mathrm{Zn}$ e $\mathrm{Mn}$ ) terem apresentado teor foliar acima da faixa descrita como adequada por Lorenzi et al. (1997), provavelmente, está relacionado como o fato de o solo estar em uma condição de baixo $\mathrm{pH}$, a qual sabidamente aumenta a disponibilidade desses elementos, podendo isso ser comprovado pelos altos teores destes no solo (Raij et al., 1997). Esses resultados indicam que as plantas foram cultivadas sob adequada disponibilidade dos micronutrientes estudados, não tendo havido limitação à adequada absorção deles.

Com relação à quantidade de micronutrientes acumulada nos diferentes órgãos das plantas, verificase que houve variação entre as cultivares quanto à quantidade presente nos tubérculos-semente
(Figuras 2a, 3a, 4a, 5a e 6a). No decorrer do ciclo, a quantidade de $\mathrm{Cu}$, Fe e Zn acumulada nos tubérculossemente diminuiu (Figuras 3a, 4a e 6a), em função da redução da MS (Fernandes et al., 2010) e da remobilização desses elementos para as regiões de crescimento. Já a quantidade de B e Mn presente nesse órgão permaneceu relativamente constante, apesar da diminuição da MS (Fernandes et al., 2010), resultado da baixa mobilidade desses elementos nos tecidos (Raven, 1980; Malavolta, 2006).

Nas raízes, houve diferença entre as cultivares quanto ao acúmulo de micronutrientes (Figuras $2 \mathrm{~b}$, $3 \mathrm{~b}, 4 \mathrm{~b}, 5 \mathrm{~b}$ e 6b). As cultivares Asterix e Atlantic apresentaram maior acúmulo de $\mathrm{B}, \mathrm{Cu}, \mathrm{Fe}$ e $\mathrm{Zn}$, enquanto o acúmulo radicular de Mn foi semelhante entre as cultivares Atlantic, Asterix, Markies e Mondial. O menor acúmulo radicular dos micronutrientes estudados foi observado na cultivar
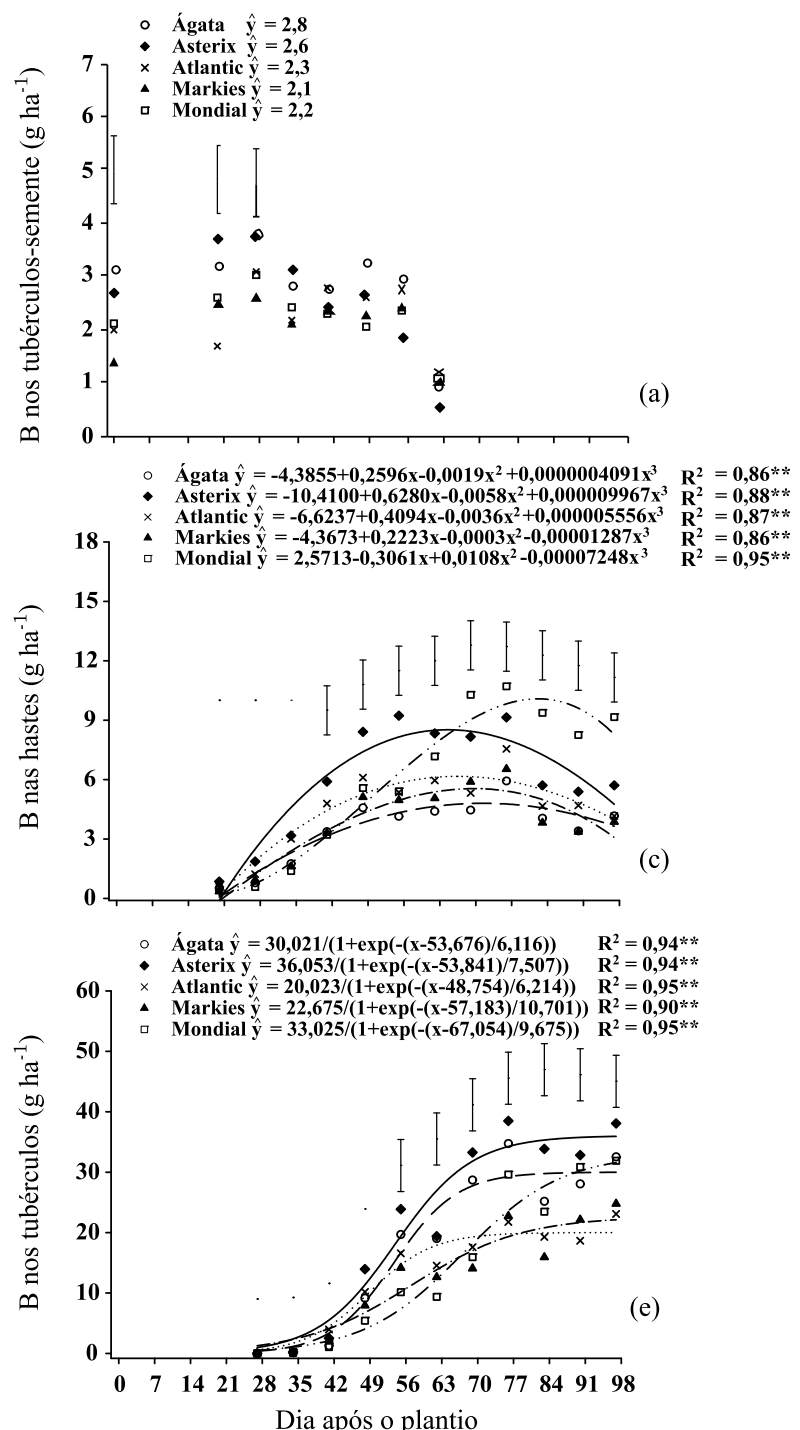
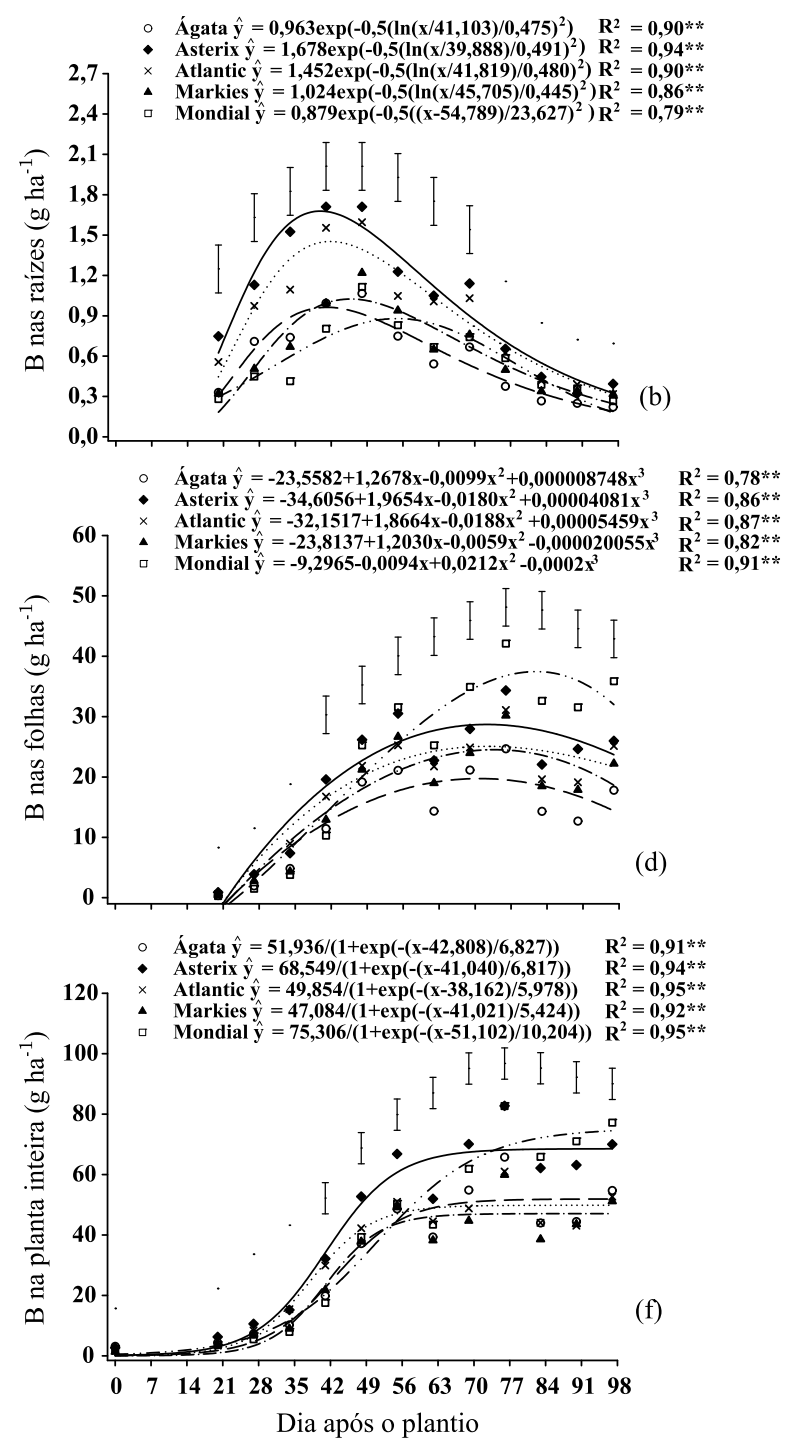

Figura 2. Quantidade de B nos tubérculos-semente (a), raízes (b), hastes (c), folhas (d), tubérculos (e) e na planta inteira (f) de cultivares de batata ao longo do ciclo. ** significativo a $1 \%$ pelo teste F. Barras verticais indicam o valor de DMS pelo teste de Tukey a $5 \%$. 

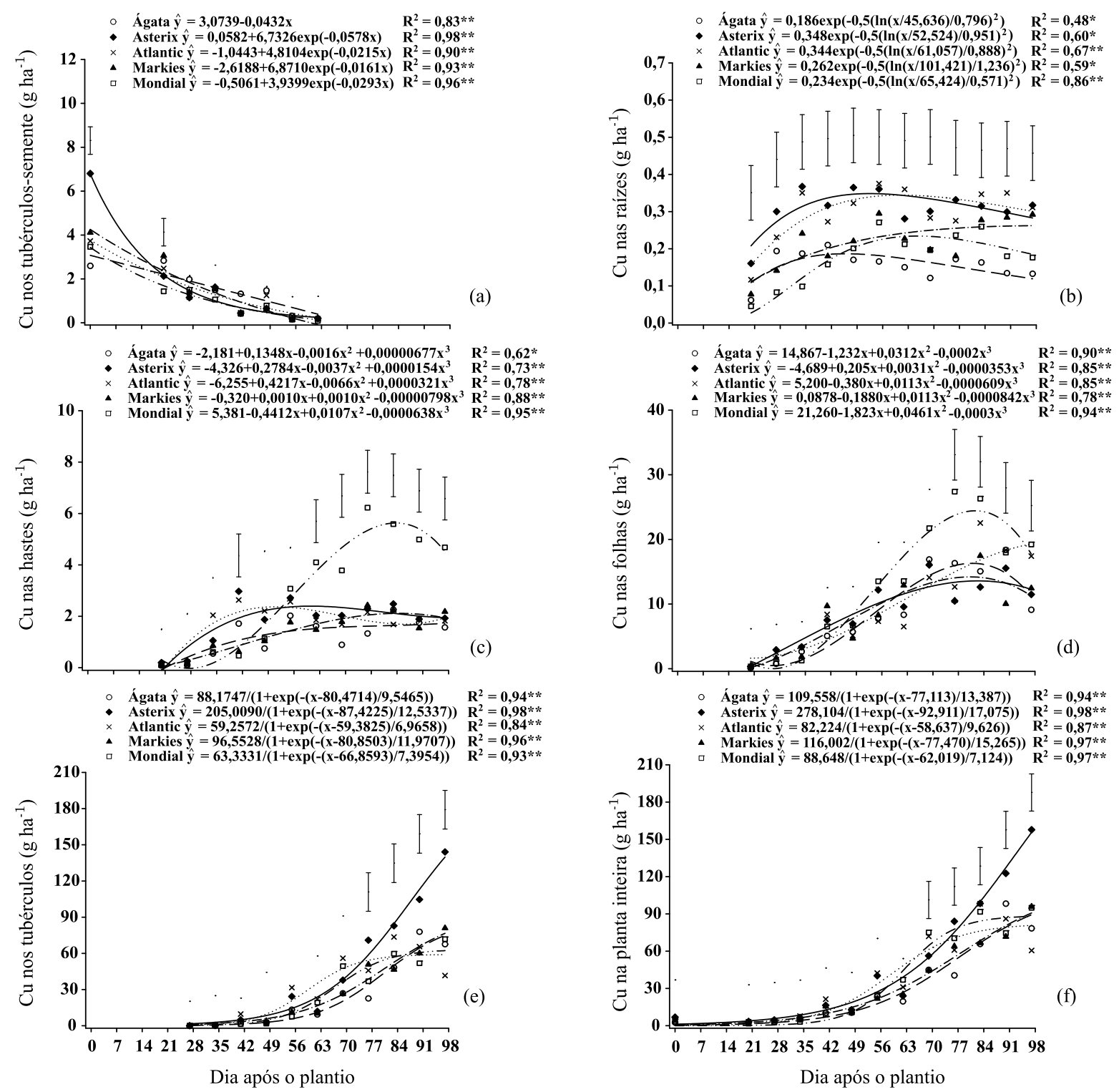

Figura 3. Quantidade de Cu nos tubérculos-semente (a), raízes (b), hastes (c), folhas (d), tubérculos (e) e na planta inteira (f) de cultivares de batata ao longo do ciclo. ** significativo a $1 \%$ pelo teste F. Barras verticais indicam o valor de DMS pelo teste de Tukey a $5 \%$.

Ágata, exceto na fase inicial do ciclo, em que ela apresentou acúmulo radicular superior ao da cultivar Mondial, provavelmente, em função da menor MS radicular desta cultivar nesse período (Fernandes et al., 2010). Na fase final do ciclo, houve redução na quantidade de $\mathrm{B}, \mathrm{Cu}, \mathrm{Fe}, \mathrm{Mn}$ e $\mathrm{Zn}$ acumulada nas raízes de todas as cultivares estudadas (Figuras $2 b$, $3 b, 4 b, 5 b$ e $6 b$ ), o que em parte é resultado da diminuição da MS radicular nesse período (Fernandes et al., 2010). Entretanto, a redução no acúmulo radicular de $\mathrm{Cu}$ foi menos intensa que a dos demais nutrientes, o que se deve ao maior incremento no teor de $\mathrm{Cu}$ durante esse período (dados não apresentados). Os micronutrientes que foram acumulados em maior quantidade nas raízes foram $\mathrm{Fe}$ e $\mathrm{Mn}$ - resultado também obtido por Paula et al. (1986) e Yorinori (2003).
Nas fases iniciais do ciclo, a quantidade de micronutrientes acumulada nas hastes foi pequena $\mathrm{e}$ não diferiu entre as cultivares (Figuras 2c, 3c, 4c, 5c e 6c). As hastes das cultivares Mondial e Asterix apresentaram acúmulo de $\mathrm{B}, \mathrm{Fe}$ e $\mathrm{Mn}$, superior ao das demais, com valores ao redor de 8,5 $\mathrm{g} \mathrm{ha}^{-1}$ (Asterix) e 10,1 $\mathrm{g} \mathrm{ha}^{-1}$ (Mondial) para B, 240,7 $\mathrm{g} \mathrm{ha}^{-1}$ (Mondial) e 186,0 $\mathrm{g} \mathrm{ha}^{-1}$ para Fe e 150,3 $\mathrm{g} \mathrm{ha}^{-1}$ (Mondial) e $108,4 \mathrm{~g} \mathrm{ha}^{-1}$ (Asterix) para Mn (Figuras 2c, 4c e 5c). Nas demais cultivares, o acúmulo de Be Fe nas hastes apresentou valores semelhantes. Já com relação ao Mn, as cultivares Ágata e Markies apresentaram o menor acúmulo desse elemento, ao passo que a cultivar Atlantic apresentou acúmulo intermediário de Mn. Diferentemente dos nutrientes $\mathrm{B}, \mathrm{Cu}, \mathrm{Fe}$ e $\mathrm{Zn}$, que apresentaram pequena redução na quantidade 
acumulada na fase final do ciclo, o acúmulo de $\mathrm{Mn}$ nas hastes continuou aumentando (Figuras 2c, 3c, 4c, $5 c$ e 6c). Quanto ao acúmulo de $\mathrm{Cu}$ e $\mathrm{Zn}$ nas hastes, verificou-se que a cultivar Mondial apresentou acúmulo superior ao observado nas demais cultivares a partir dos 55 DAP, enquanto as demais cultivares acumularam quantidade semelhante desses elementos durante o ciclo (Figuras 3c e 6c).

Houve acúmulo de micronutrientes nas folhas de todas as cultivares até próximo ao final do ciclo, com redução acentuada da quantidade acumulada nas duas últimas semanas (Figuras 2c, 3d, 4d, 5d e 6d). Apenas a cultivar Atlantic apresentou acúmulo crescente de $\mathrm{Cu}$ e $\mathrm{Zn}$ nas folhas até o final do ciclo (Figuras 3d e 6d). O maior acúmulo de B, Cu, Fe e $\mathrm{Zn}$ nas folhas foi observado na cultivar Mondial, enquanto nas demais a quantidade acumulada foi semelhante (Figuras 2d, 3d, 4d e 6d). Quanto ao acúmulo de $\mathrm{Mn}$, verificou-se que, com exceção da cultivar Ágata, que obteve o maior acúmulo desse elemento, todas as demais acumularam quantidade semelhante de Mn nas folhas durante o ciclo (Figura 5d).

$\mathrm{O}$ Fe e o Mn foram os micronutrientes acumulados em maior quantidade nas folhas e hastes, ou seja, na parte aérea das plantas de batata (Figuras 4 e 5). A quantidade desses elementos acumulada na parte aérea foi superior àquela acumulada nos tubérculos, demonstrando que os tubérculos não são os principais drenos de Fe e Mn na planta de batata. Paula et al. (1986), Yorinori (2003) e Cabalceta et al. (2005) também obtiveram acúmulo de Fe e Mn em maior proporção na parte aérea da batateira que nos tubérculos.
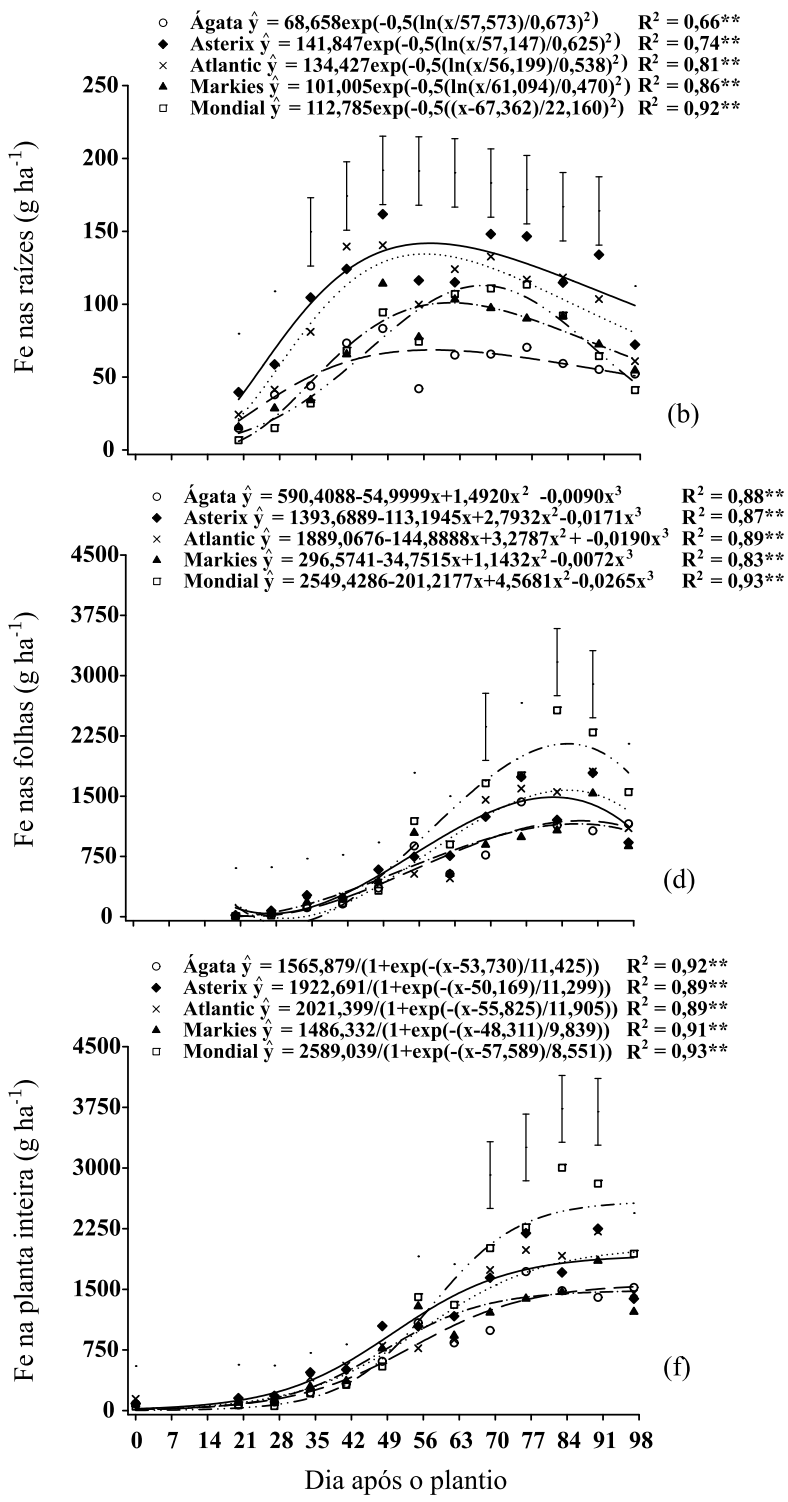

Figura 4. Quantidade de Fe nos tubérculos-semente (a), raízes (b), hastes (c), folhas (d), tubérculos (e) e na planta inteira (f) de cultivares de batata ao longo do ciclo. $*$ e $* *$ : significativos a 5 e $1 \%$ pelo teste F. Barras verticais indicam o valor de DMS pelo teste de Tukey a $5 \%$. 
Esse padrão de distribuição do Fe e Mn em favor das folhas e hastes está relacionado com sua função no metabolismo da planta. O Fe atua como ativador enzimático na síntese da clorofila, participa da fotossíntese e da respiração (Malavolta, 2006; Dechen \& Nachtigall, 2006) e da síntese e desenvolvimento dos cloroplastos, alterando o tamanho e o conteúdo de proteínas nos cloroplastos (Marschner, 1995). Por isso, esse elemento é utilizado sobretudo na parte aérea (Cabalceta et al., 2005), uma vez que, após absorvido, seu transporte a longa distância é feito, principalmente, via xilema e sua mobilização para dentro do floema é diminuída pela formação de compostos insolúveis nas folhas (Taiz \& Zeiger, 2004; Dechen \& Nachtigall, 2006). Isso justifica seu maior acúmulo nas folhas em comparação aos demais órgãos das plantas (Figura 4). Segundo Cabalceta et al. (2005), o Mn acumula-se em sua maioria na parte aérea, onde atua como
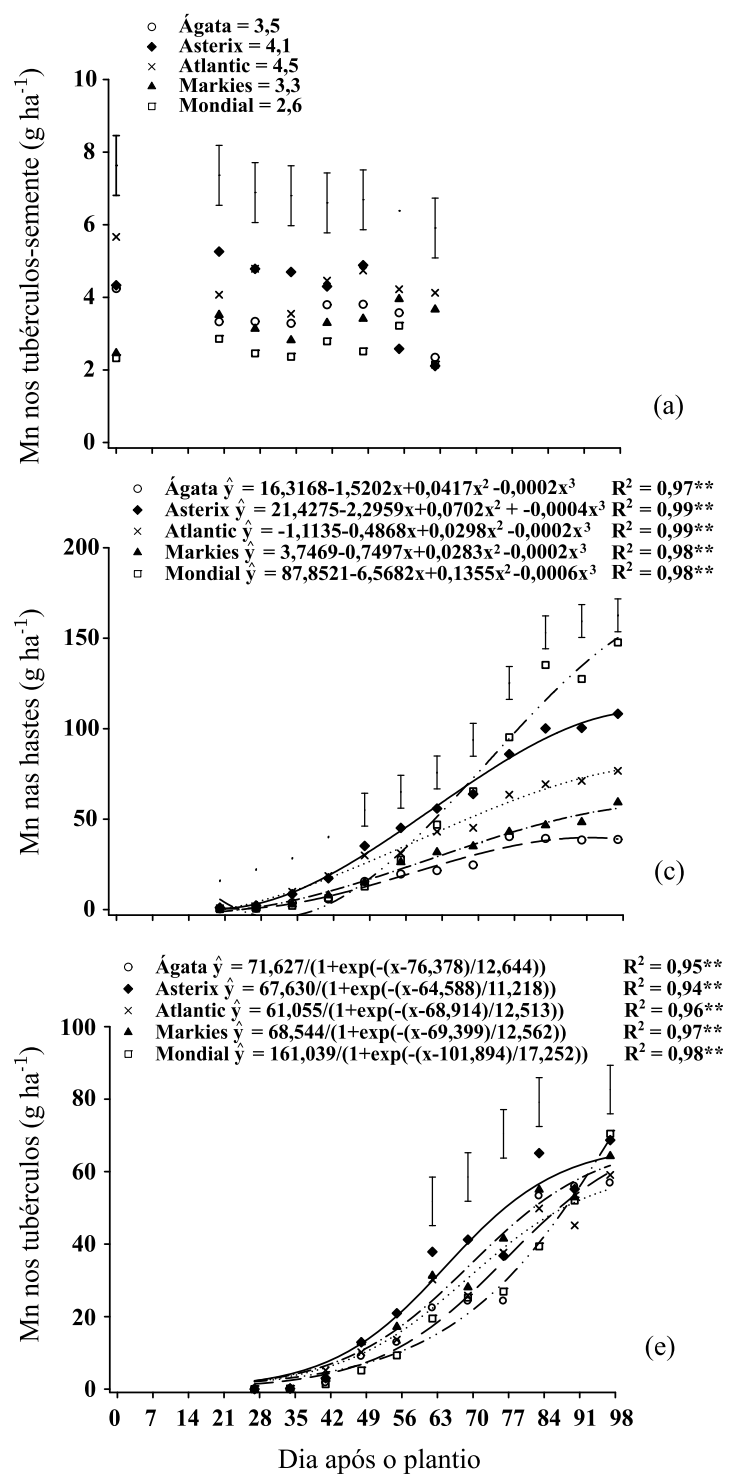

ativador enzimático no processo de respiração e participa da fotólise da água durante a fotossíntese (Malavolta, 2006). Assim, o acúmulo preferencial de Mn na parte aérea ocorre em função da sua pequena redistribuição dentro da planta, pois, após absorvido, esse elemento move-se livremente via corrente transpiratória e acumula-se em certos órgãos das plantas, como as folhas (Malavolta, 2006); o pequeno transporte que ocorre via floema é responsável pela baixa concentração desse elemento em frutos, sementes e órgãos de reserva (Dechen \& Nachtigall, 2006), que, nesse caso, são os tubérculos.

A quantidade de $\mathrm{B}, \mathrm{Cu}, \mathrm{Mn}$ e $\mathrm{Zn}$ acumulada nos tubérculos diferiu entre as cultivares estudadas, e o acúmulo de $\mathrm{Fe}$ no referido órgão foi semelhante (Figuras 2e, 3e, 4e, 5e e 6e). Do início da tuberização (34 DAP) até por volta dos 55 DAP, a quantidade de $\mathrm{Cu}, \mathrm{Fe}, \mathrm{Mn}$ e $\mathrm{Zn}$ acumulada nos tubérculos aumentou
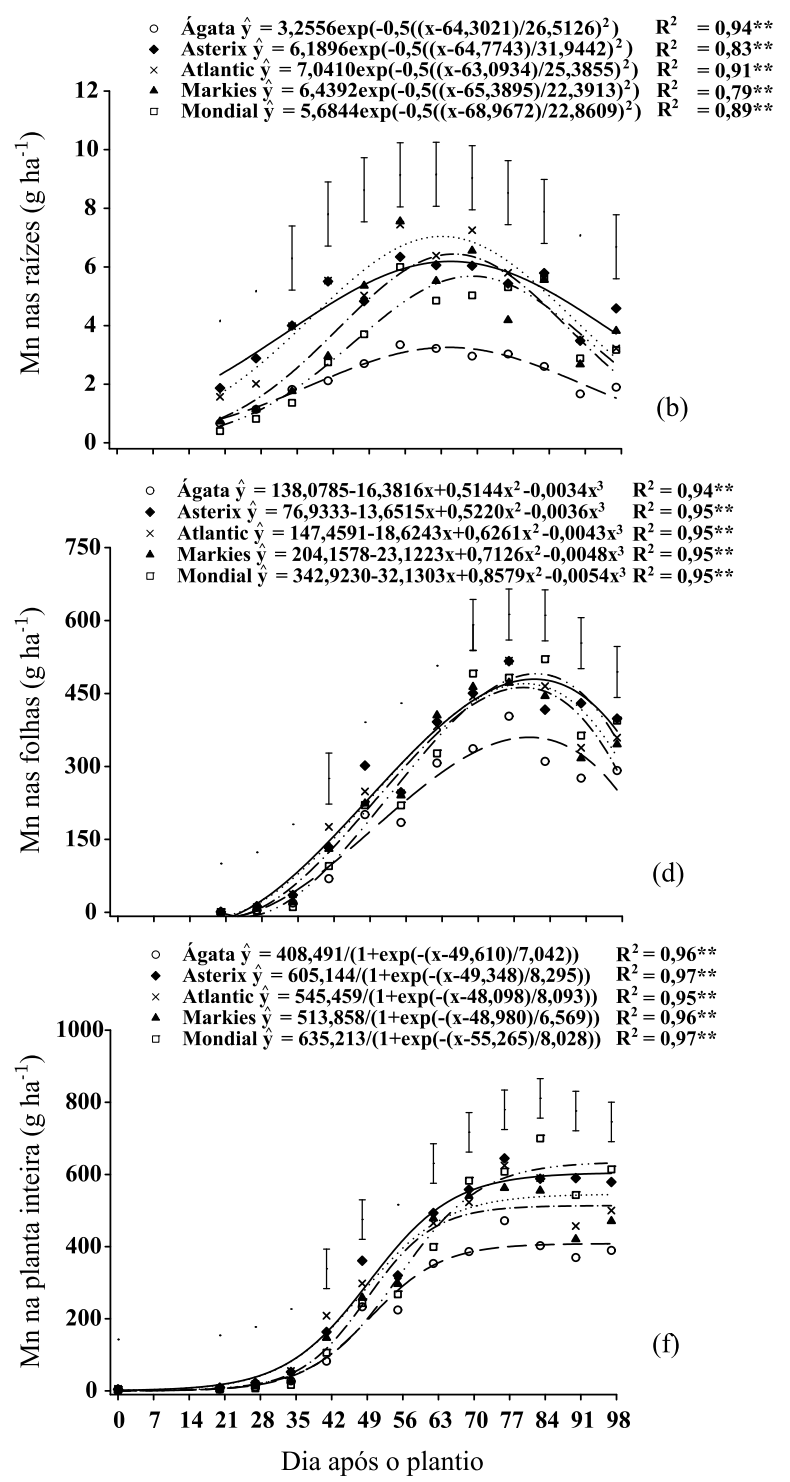

Figura 5. Quantidade de Mn nos tubérculos-semente (a), raízes (b), hastes (c), folhas (d), tubérculos (e) e na planta inteira (f) de cultivares de batata ao longo do ciclo. ** significativo a $1 \%$ pelo teste F. Barras verticais indicam o valor de DMS pelo teste de Tukey a $5 \%$. 
lentamente; após esse período, o acúmulo intensificouse até o final do ciclo.

Quanto ao B, houve aumento na quantidade acumulada nos tubérculos a partir dos 48 DAP, ou seja, numa fase mais inicial do ciclo em comparação aos demais micronutrientes (Figuras 2e, 3e, 4e, 5e e 6e). $\mathrm{O}$ acúmulo de $\mathrm{B}$ nos tubérculos aumentou intensamente até por volta dos 76 DAP nas cultivares Asterix, Ágata e Atlantic, e até os 90 DAP nas cultivares Markies e Mondial (Figura 2e). O acúmulo intenso de $\mathrm{B}$ nos tubérculos a partir do início da formação destes deve-se ao fato de que o B participa do crescimento e da divisão celular dos tecidos meristemáticos, da formação de paredes celulares e atua na translocação de amido da parte aérea para os tubérculos (Cabalceta et al., 2005). Dessa forma, em razão de o desenvolvimento dos tubérculos ser precedido de intenso processo de divisão e alongamento celular na região subapical do estolão (Struik et al.,
1999), é comum o rápido acúmulo de B em tubérculos em formação (Bertsch, 1998; Cabalceta et al., 2005). No final do ciclo, o acúmulo de B nos tubérculos das cultivares Asterix (36 $\left.\mathrm{g} \mathrm{ha}^{-1}\right)$, Mondial (31 $\left.\mathrm{g} \mathrm{ha}^{-1}\right) \mathrm{e}$ Ágata $\left(30 \mathrm{~g} \mathrm{ha}^{-1}\right)$ foi superior ao observado nas demais, devido, principalmente, ao maior acúmulo de MS nos tubérculos de Asterix e Mondial (Fernandes et al., 2010), bem como aos maiores valores das taxas máximas de acúmulo de $\mathrm{B}$ nos tubérculos das cultivares Asterix e Ágata e ao maior período de duração das taxas de acúmulo nos tubérculos de Mondial (Figura 2e e Quadro 2). Paula et al. (1986) obtiveram acúmulo máximo de $\mathrm{B}$ nos tubérculos de 22,2 $\mathrm{g} \mathrm{ha}^{-1}$, enquanto Yorinori (2003) obteve acúmulo de até $75,3 \mathrm{~g} \mathrm{ha}^{-1}$ de $\mathrm{B}$ nos tubérculos, durante a safra das águas.

As cultivares Markies e Atlantic, que acumularam a menor quantidade de B nos tubérculos (Figura 2e), apresentaram taxas de acúmulo com valores baixos

Quadro 2. Quantidade máxima acumulada, taxa diária máxima de acúmulo, duração da taxa diária máxima de acúmulo e período até a taxa diária máxima de acúmulo de $\mathrm{B}, \mathrm{Cu}, \mathrm{Fe}$, Mn e Zn nos tubérculos e na planta inteira de cultivares de batata

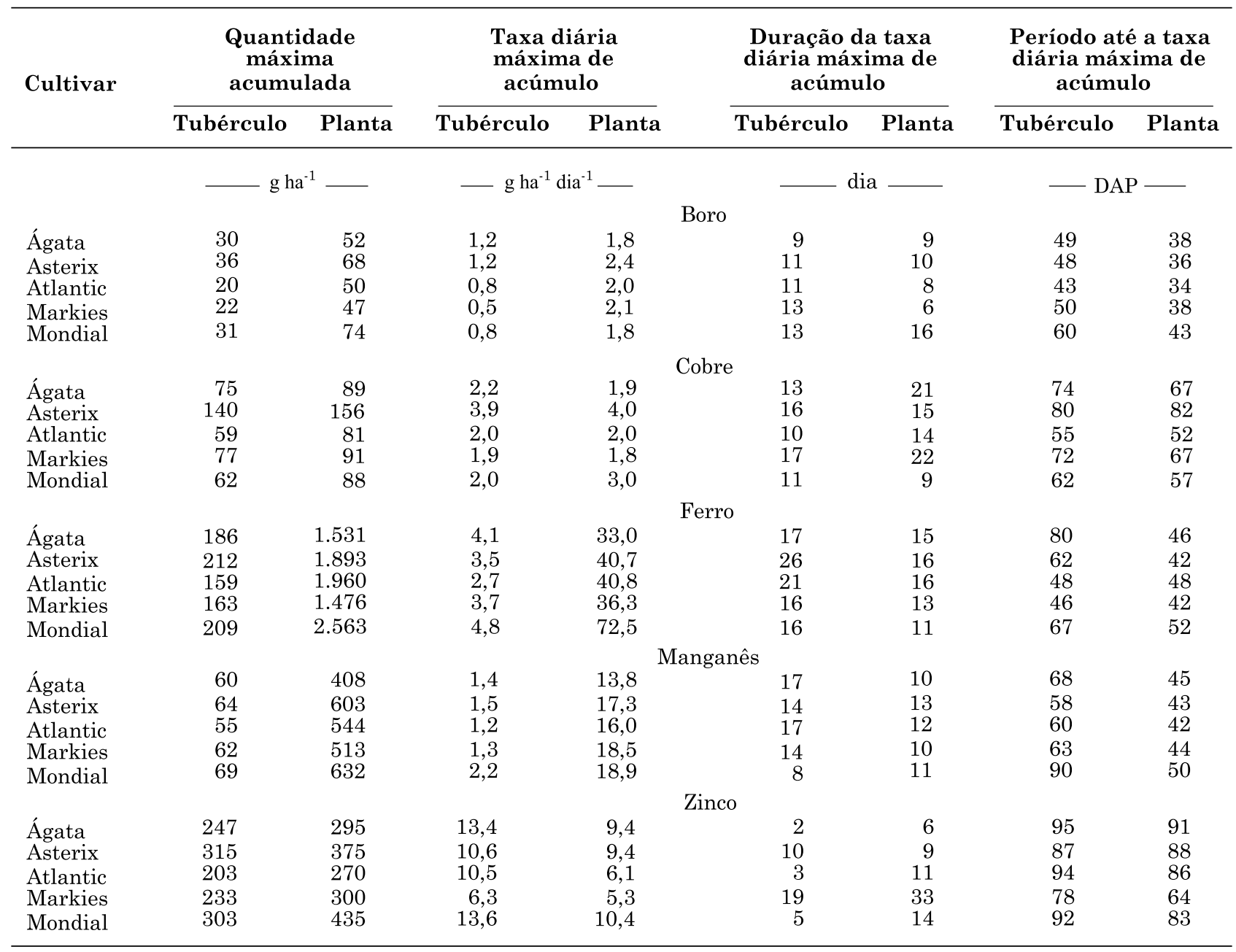

Valores obtidos nas equações ajustadas das figuras $2,3,4,5$ e 6. DAP: dias após o plantio. 
(Markies) e com períodos de duração curtos (Atlantic) (Quadro 2). A cultivar Mondial, que acumulou quantidade de $\mathrm{B}$ nos tubérculos superior às observadas em Atlantic e Markies, apresentou taxas de acúmulo de $\mathrm{B}$ nos tubérculos semelhantes às de Atlantic, porém seu maior período de duração das taxas de acúmulo proporcionou maior acúmulo desse elemento (Quadro 2 e Figura 2e). O B foi o micronutriente que apresentou distribuição mais proporcional entre as folhas e os tubérculos, uma vez que as cultivares Asterix, Mondial e Ágata, que acumularam nos tubérculos, respectivamente, 36, 31 e $30 \mathrm{~g} \mathrm{ha}^{-1}$, chegaram a atingir acúmulo máximo nas folhas de 28,7, 37,5 e 19,7 $\mathrm{g} \mathrm{ha}^{-1}$, respectivamente. Cabalceta et al. (2005) relatam que a quantidade de B absorvida pela batateira distribui-se em partes iguais entre a folhagem e os tubérculos - fato que também foi observado neste estudo.

Com relação ao acúmulo de $\mathrm{Cu}$ nos tubérculos, nota-se que o maior acúmulo foi obtido na cultivar Asterix, ou seja, aquela que apresentou o maior valor da taxa e do período de duração da taxa de acúmulo de $\mathrm{Cu}$ nos tubérculos (Figura 3e e Quadro 2). Embora a cultivar Markies tenha apresentado período de duração da taxa de acúmulo de Cu nos tubérculos maior que o obtido em Asterix, o valor da taxa foi menor, o que levou ao menor acúmulo desse elemento (Figura $3 \mathrm{e}$ e Quadro 2). Quanto ao acúmulo de Fe, Mn e Zn nos tubérculos, as cultivares Mondial e Asterix, que apresentaram elevados valores e, ou, períodos de duração das taxas de acúmulo desses elementos (Quadro 2), acumularam quantidade relativamente superior à das demais cultivares (Figuras 4e, 5e e 6e).

O B apresentou distribuição proporcional entre as folhas e os tubérculos, e os micronutrientes Fe e Mn acumularam-se preferencialmente nas folhas (Figuras 2, 4 e 5). Já os micronutrientes $\mathrm{Cu}$ e $\mathrm{Zn}$ apresentaram acúmulo preferencial nos tubérculos, visto que a quantidade acumulada nesse órgão foi superior à observada na parte aérea (Figuras 3 e 6), conforme também observado por outros autores (Paula et al., 1986; Yorinori, 2003; Cabalceta et al., 2005). Além disso, as taxas de acúmulo de $\mathrm{Cu}$ e $\mathrm{Zn}$ nos tubérculos foram semelhantes $(\mathrm{Cu})$ ou até superiores (Zn) às observadas na planta inteira (Quadro 2), demonstrando que, durante parte do período de duração das taxas máximas de acúmulo desses elementos, a quantidade absorvida foi direcionada quase que em sua totalidade para os tubérculos. Cabalceta et al. (2005) também observaram certa translocação de $\mathrm{Zn}$ da parte aérea para os tubérculos na fase final do ciclo da batateira. O acúmulo preferencial de Fe e Mn na parte aérea fica evidente quando se verifica que os valores das taxas de acúmulo nos tubérculos foram bem inferiores aos das taxas de acúmulo nas plantas inteiras (Quadro 2), o que demonstra que a maior parte do $\mathrm{Fe}$ e $\mathrm{Mn}$ absorvidos fica retida nas folhas e não é direcionada aos tubérculos.
Considerando as plantas inteiras, nota-se que houve pequeno aumento na quantidade acumulada de micronutrientes até o início da fase de enchimento de tubérculos (Figuras 2f, 3f, 4f, 5f e 6f). Houve diferenças entre as cultivares com relação à quantidade total de micronutrientes absorvida durante o ciclo, demonstrando que elas apresentam exigências nutricionais diferentes. O B foi o micronutriente acumulado mais precocemente durante o ciclo, pois até o início da fase de enchimento de tubérculos (42 DAP) as cultivares Asterix, Atlantic e Markies já tinham absorvido entre 50 e $61 \%$ da necessidade total (Quadro 3). Após a tuberização, a quantidade de B acumulada pelas plantas continuou aumentando até por volta dos 62 DAP, com posterior estabilização (Figura 2f). Paula et al. (1986) e Yorinori (2003), na safra das secas, observaram acúmulo crescente de B pelas plantas de batata até por volta dos 80 DAP, porém, na safra das águas, Yorinori (2003) verificou que o acúmulo de $\mathrm{B}$ aumentou até o final do ciclo. Já a quantidade acumulada de $\mathrm{Fe}$ e $\mathrm{Mn}$ aumentou até 83 DAP, mantendo-se relativamente constante (Figuras $4 \mathrm{f}$ e $5 \mathrm{f}$ ), uma vez que dos 42 aos 62 DAP as cultivares absorveram entre 42 e $51 \%$ do Fe e 56 e $63 \%$ do Mn exigidos durante o ciclo (Quadro 3). Os micronutrientes $\mathrm{Cu}$ e $\mathrm{Zn}$ tiveram dinâmica de acúmulo semelhante, com aumento na quantidade acumulada a partir da fase de enchimento de tubérculos até o final do ciclo (Figuras $3 \mathrm{f}$ e $6 \mathrm{f}$ ).

Os períodos de maior demanda das plantas por B, ou seja, as épocas de ocorrência das maiores taxas de acúmulo, foram dos 34 DAP (Atlantic) aos 59 DAP (Mondial), ao passo que as maiores demandas por $\mathrm{Fe}$ e Mn ocorreram entre 42 DAP (Atlantic) e 63 DAP (Mondial) e entre 42 DAP (Atlantic) e 61 DAP (Mondial), respectivamente (Quadro 2). Os micronutrientes $\mathrm{Cu}$ e $\mathrm{Zn}$ foram absorvidos em maiores taxas entre 52 DAP (Atlantic) e 97 DAP (Mondial) e entre 64 DAP (Markies) e 97 DAP (Mondial), respectivamente, ou seja, na fase final do ciclo.

As cultivares Mondial e Asterix acumularam maior quantidade de B e Zn durante o ciclo (Figuras $2 \mathrm{f}$ e $6 f$ ), devido, em parte, à maior taxa de acúmulo de $B$ apresentada por Asterix e ao longo período de duração da taxa de acúmulo da cultivar Mondial (Quadro 2). Embora a cultivar Markies tenha apresentado longo período de duração da taxa máxima de acúmulo de $\mathrm{Zn}$, o valor da taxa foi pequeno, o que refletiu em acúmulo inferior ao das cultivares Mondial e Asterix (Quadro 2).

Quanto ao acúmulo de $\mathrm{Cu}$ nas plantas, nota-se que a cultivar Asterix, que apresentou elevada taxa de acúmulo desse elemento, acumulou a maior quantidade de $\mathrm{Cu}$, enquanto as cultivares Ágata, Atlantic e Markies, que apresentaram taxas de acúmulo e períodos de duração similares, não diferiram quanto ao total desse nutriente acumulado (Figura $3 \mathrm{f}$ e Quadro 2). Na cultivar Mondial, o maior valor da taxa de acúmulo de $\mathrm{Cu}$ compensou o baixo período de 
Quadro 3. Percentual de B, Cu, Fe, Mn e Zn acumulado em cada fase do desenvolvimento das plantas de cultivares de batata

\begin{tabular}{|c|c|c|c|c|c|}
\hline \multirow{3}{*}{ Cultivar } & \multicolumn{5}{|c|}{ Dias após o plantio/Fases da cultura } \\
\hline & $0-34$ & $35-41$ & $42-62$ & 63-90 & \multirow{2}{*}{$\begin{array}{c}91-97 \\
\text { Maturação }\end{array}$} \\
\hline & Crescimento vegetativo & Tuberização & \multicolumn{2}{|c|}{$\overline{\text { Enchimento de tubérculos }}$} & \\
\hline & \multicolumn{5}{|c|}{$-\%$} \\
\hline & \multicolumn{5}{|c|}{ Boro } \\
\hline Ágata & 22 & 21 & 51 & 6 & 0 \\
\hline Asterix & 27 & 23 & 46 & 4 & 0 \\
\hline Atlantic & 33 & 28 & 37 & 2 & 0 \\
\hline Markies & 22 & 28 & 48 & 2 & 0 \\
\hline Mondial & 16 & 11 & 48 & 24 & 1 \\
\hline & \multicolumn{5}{|c|}{ Cobre } \\
\hline Ágata & 5 & 3 & 22 & 59 & 11 \\
\hline Asterix & 5 & 3 & 17 & 57 & 18 \\
\hline Atlantic & 7 & 7 & 45 & 39 & 2 \\
\hline Markies & 7 & 3 & 22 & 55 & 13 \\
\hline Mondial & 2 & 3 & 46 & 48 & 1 \\
\hline & \multicolumn{5}{|c|}{ Ferro } \\
\hline Ágata & 16 & 9 & 44 & 29 & 2 \\
\hline Asterix & 20 & 12 & 44 & 23 & 1 \\
\hline Atlantic & 14 & 9 & 42 & 33 & 2 \\
\hline Markies & 19 & 13 & 49 & 18 & 1 \\
\hline Mondial & 6 & 7 & 51 & 35 & 1 \\
\hline & \multicolumn{5}{|c|}{ Manganês } \\
\hline Ágata & 10 & $13^{\text {Indat }}$ & 63 & 14 & 0 \\
\hline Asterix & 14 & 13 & 56 & 17 & 0 \\
\hline Atlantic & 15 & 14 & 56 & 15 & 0 \\
\hline Markies & 10 & 13 & 65 & 12 & 0 \\
\hline Mondial & 7 & 7 & 56 & 29 & 1 \\
\hline & \multicolumn{5}{|c|}{ Zinco } \\
\hline Ágata & 9 & 3 & 16 & 50 & 22 \\
\hline Asterix & 12 & 4 & 18 & 49 & 17 \\
\hline Atlantic & 15 & 4 & 18 & 47 & 16 \\
\hline Markies & 11 & 4 & 23 & 50 & 12 \\
\hline Mondial & 9 & 3 & 18 & 53 & 17 \\
\hline
\end{tabular}

Valores obtidos nas equações ajustadas das figuras $2,3,4,5$ e 6 .

duração desta, proporcionando acúmulo semelhante ao observado nas cultivares Ágata, Atlantic e Markies.

A cultivar Mondial, que apresentou a maior taxa de acúmulo de Fe, extraiu a maior quantidade desse elemento, enquanto as cultivares Asterix e Atlantic, que apresentaram taxas de acúmulo de Fe similares, porém inferiores à obtida pela cultivar Mondial, acumularam quantidade intermediária de Fe (Quadro 2 e Figura 4f). As cultivares Ágata e Markies, que apresentaram as menores taxas de acúmulo de $\mathrm{Fe}$, acumularam menor quantidade desse elemento.

Com relação ao Mn, verifica-se que as cultivares Mondial, Asterix, Atlantic e Markies, que apresentaram valor e período de duração das taxas de acúmulo relativamente elevados e semelhantes, acumularam maior quantidade de Mn durante o ciclo, em comparação com a cultivar Ágata, que apresentou o menor valor da taxa e, consequentemente, menor acumulação desse elemento (Quadro 2 e Figura 5f).
A quantidade de micronutrientes extraída pelas plantas obedeceu à seguinte sequência: $\mathrm{Fe}>\mathrm{Mn}>\mathrm{Zn}$ $>\mathrm{Cu}>\mathrm{B}$, com valores médios de 1.885, 540, 335, $101 \mathrm{e}$ $58 \mathrm{~g} \mathrm{ha}^{-1}$, respectivamente. (Figuras 2f, 3f, 4f, $5 \mathrm{f} \mathrm{e} 6 \mathrm{f} \mathrm{e}$ Quadro 2). Yorinori (2003) observou sequência de extração semelhante, em que apenas o B foi mais extraído que o Cu. Paula et al. (1986) observaram a mesma sequência de extração relatada por Yorinori (2003) para a cultivar Mantiqueira sob adubação; entretanto, para a mesma cultivar sem adubação e para a cultivar Achat com e sem adubação, a sequência de extração foi a mesma do presente estudo. Cabalceta et al. (2005), estudando a absorção de nutrientes em diferentes localidades, também observaram alteração na ordem de extração de $\mathrm{Cu}$ e B, dependendo da região de cultivo.

As cultivares que apresentaram maior acúmulo durante o ciclo chegaram a acumular $74 \mathrm{~g} \mathrm{ha}^{-1}$ de B (Mondial), $156 \mathrm{~g} \mathrm{ha}^{-1} \mathrm{de} \mathrm{Cu}$ (Asterix), $2.563 \mathrm{~g} \mathrm{ha}^{-1} \mathrm{de}$ Fe (Mondial), $632 \mathrm{~g} \mathrm{ha}^{-1}$ de Mn (Mondial) e $435 \mathrm{~g} \mathrm{ha}^{-1}$ de $\mathrm{Zn}$ (Mondial), ao passo que as cultivares que 

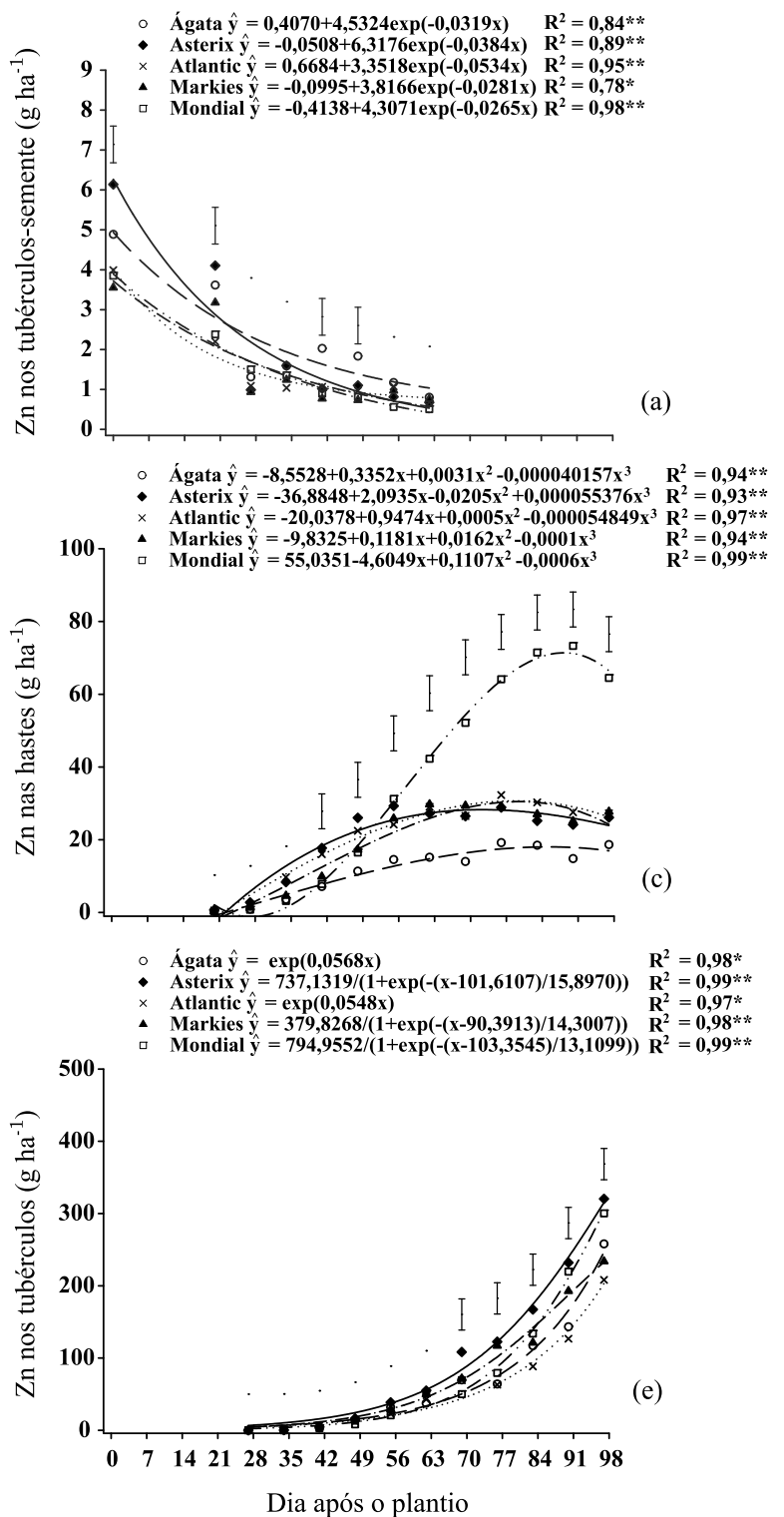
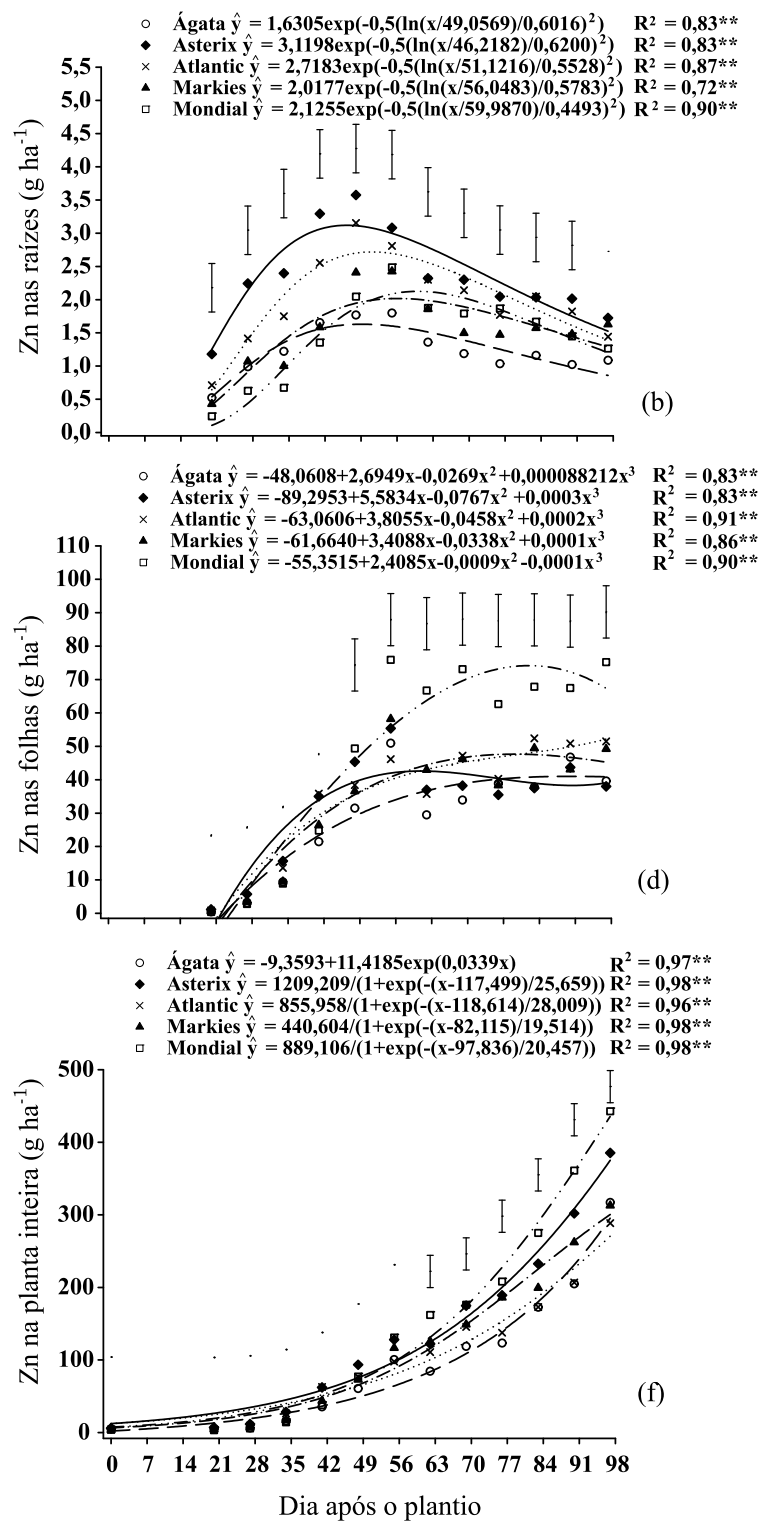

Figura 6. Quantidade de Zn nos tubérculos-semente (a), raízes (b), hastes (c), folhas (d), tubérculos (e) e na planta inteira (f) de cultivares de batata ao longo do ciclo. * e **: significativos a 5 e $1 \%$ pelo teste F. Barras verticais indicam o valor de DMS pelo teste de Tukey a $5 \%$.

acumularam menor quantidade absorveram em torno de $47 \mathrm{~g} \mathrm{ha}^{-1}$ de B (Markies), $81 \mathrm{~g} \mathrm{ha}^{-1}$ de $\mathrm{Cu}$ (Atlantic), $1.476 \mathrm{~g} \mathrm{ha}^{-1} \mathrm{de}$ Fe (Markies), $408 \mathrm{~g} \mathrm{ha}^{-1} \mathrm{de} \mathrm{Mn} \mathrm{(Ágata)}$ e $270 \mathrm{~g} \mathrm{ha}^{-1}$ de Zn (Atlantic) (Figuras 2f, 3f, 4f, 5f e $6 \mathrm{f}$ e Quadro 2).

Com base na dinâmica de acúmulo dos micronutrientes, verifica-se que, quando indicadas aplicações de micronutrientes em cobertura, é conveniente realizar aplicações aos 34-43 DAP com B, 42-50 DAP com Fe e Mn e a partir dos 64 DAP com $\mathrm{Cu}$ e Zn, para que haja adequada disponibilidade desses nutrientes durante a fase crítica de acúmulo, principalmente em solos pobres nesses nutrientes.

Quanto à exportação de micronutrientes, verificase que as cultivares Ágata e Asterix apresentaram maior exportação de $\mathrm{B}$, embora o teor desse elemento nos tubérculos não tenha apresentado grande variação (Quadro 4). Já a exportação relativa de B diferiu apenas entre a cultivar Mondial e as cultivares Ágata e Asterix, com valores variando entre $0,7 \mathrm{~g}$ (Mondial) a $1,2 \mathrm{~g}$ de $\mathrm{B}$ para cada tonelada de tubérculos (Quadro 4). As cultivares Asterix, Markies e Mondial tiveram exportação de $\mathrm{Cu}$ relativamente superior à das demais cultivares, resultado da maior produção de MS de tubérculos apresentada pela Asterix (Fernandes et al., 2010) e do maior teor de $\mathrm{Cu}$ nos tubérculos de Markies e Mondial (Quadro 4). A exportação de $\mathrm{Cu}$ por tonelada de tubérculos diferiu apenas entre a cultivar Ágata e as cultivares Markies e Mondial, possivelmente em razão da menor exportação por área obtida em Ágata (Quadro 4) e da 
Quadro 4. Teor e exportação de B, Cu, Fe, Mn e Zn nos tubérculos de cultivares de batata no momento da colheita

\begin{tabular}{|c|c|c|c|c|c|}
\hline Cultivar & B & $\mathbf{C u}$ & $\mathbf{F e}$ & Mn & $\mathrm{Zn}$ \\
\hline \multicolumn{6}{|c|}{ Teor nos tubérculos, $\mathrm{mg} \mathrm{kg}^{-1(1)}$} \\
\hline Ágata & $8 a$ & $4 \mathrm{~b}$ & $56 a$ & $12 \mathrm{ab}$ & $22 \mathrm{a}$ \\
\hline Asterix & $7 \mathrm{ab}$ & $7 \mathrm{bc}$ & $47 \mathrm{a}$ & $8 \mathrm{~b}$ & $25 \mathrm{a}$ \\
\hline Atlantic & $5 \mathrm{~b}$ & $4 \mathrm{~b}$ & $57 \mathrm{a}$ & $9 b$ & $19 a$ \\
\hline Markies & $6 a b$ & $11 \mathrm{ab}$ & $27 \mathrm{~b}$ & $13 a$ & $22 \mathrm{a}$ \\
\hline Mo & $6 a b$ & $14 \mathrm{a}$ & $43 a$ & $10 \mathrm{ab}$ & $20 \mathrm{a}$ \\
\hline $\mathrm{CV}(\%)$ & 18,0 & 37,9 & 38,2 & 18,5 & 18,1 \\
\hline \multicolumn{6}{|c|}{ Quantidade exportada, $\mathrm{g} \mathrm{ha}^{-1}$} \\
\hline Ágata & $43 \mathrm{a}$ & $20 \mathrm{~b}$ & $296 \mathrm{a}$ & $62 \mathrm{ab}$ & $114 \mathrm{ab}$ \\
\hline Asterix & $48 \mathrm{a}$ & $46 a b$ & $309 a$ & $51 \mathrm{ab}$ & $167 \mathrm{a}$ \\
\hline Atlantic & $22 \mathrm{~b}$ & $16 \mathrm{~b}$ & $241 \mathrm{a}$ & $37 \mathrm{~b}$ & $83 \mathrm{~b}$ \\
\hline Markies & $30 \mathrm{~b}$ & $54 \mathrm{ab}$ & $131 \mathrm{a}$ & $65 \mathrm{a}$ & $110 \mathrm{~b}$ \\
\hline Mondial & $30 \mathrm{~b}$ & $79 a$ & $237 \mathrm{a}$ & $54 \mathrm{ab}$ & $110 \mathrm{~b}$ \\
\hline CV (\%) & 13,6 & 46,5 & 44,5 & 21,4 & 21,2 \\
\hline \multicolumn{6}{|c|}{ Exportação relativa, $\mathrm{g} \mathrm{t}^{-1}$ de tubérculo } \\
\hline Ágata & $1,17 \mathrm{a}$ & $0,52 b$ & $7,92 \mathrm{a}$ & $1,67 \mathrm{ab}$ & $3,07 \mathrm{a}$ \\
\hline Asterix & $1,20 \mathrm{a}$ & $1,15 \mathrm{ab}$ & $7,80 \mathrm{a}$ & $1,30 \mathrm{~b}$ & $4,17 \mathrm{a}$ \\
\hline Atlantic & $1,00 \mathrm{ab}$ & $0,75 \mathrm{ab}$ & $10,77 \mathrm{a}$ & $1,62 \mathrm{ab}$ & $3,70 \mathrm{a}$ \\
\hline Markies & $1,02 \mathrm{ab}$ & $1,90 \mathrm{a}$ & $4,57 \mathrm{a}$ & $2,27 \mathrm{a}$ & $3,82 \mathrm{a}$ \\
\hline Mondial & $0,72 \mathrm{~b}$ & $1,92 \mathrm{a}$ & $5,77 \mathrm{a}$ & $1,35 \mathrm{~b}$ & $2,70 \mathrm{a}$ \\
\hline $\mathrm{CV}(\%)$ & 15,9 & 43,2 & 40,5 & 22,6 & 19,9 \\
\hline
\end{tabular}

(1) Valores expressos na matéria seca. Médias seguidas de mesma letra nas colunas não diferem entre si pelo teste de Tukey a $5 \%$.

produtividade relativamente elevada (Fernandes et al., 2010), que reduziu a exportação relativa do elemento em comparação à das demais cultivares, que apresentaram maior exportação por área (Asterix, Markies e Mondial) (Quadro 4) e, ou, menor produtividade (Atlantic) (Fernandes et al., 2010).

Embora a cultivar Markies tenha apresentado teor de $\mathrm{Fe}$ nos tubérculos menor que o das demais cultivares, a exportação de Fe tanto por área quanto por tonelada de tubérculos não diferiu entre elas (Quadro 4). No que se refere à exportação de Mn, verifica-se que a cultivar Atlantic exportou a menor quantidade desse nutriente, devido ao baixo teor de Mn nos tubérculos (Quadro 4) e baixa produção de MS de tubérculos (Fernandes et al., 2010). Embora Asterix tenha apresentado baixo teor de Mn nos tubérculos, a produção de MS foi alta, como descrito por Fernandes et al. (2010), o que refletiu em exportação semelhante à observada em Ágata, Markies e Mondial. No entanto, a exportação relativa de Mn foi menor nas cultivares Asterix e Mondial (Quadro 4), o que é reflexo das elevadas produtividades apresentadas por elas (Fernandes et al., 2010), uma vez que a exportação por área foi semelhante (Quadro 4).

O teor e a exportação relativa de $\mathrm{Zn}$ não diferiram entre as cultivares, porém Ágata e Asterix apresentaram maior exportação desse nutriente da área de cultivo (Quadro 4), o que é resultado da elevada produção de MS de tubérculos (Fernandes et al., 2010).
Mesmo tendo apresentado produção de MS semelhante à da Ágata, a cultivar Mondial mostrou menor exportação de $\mathrm{Zn}$, em razão do menor teor do nutriente nos tubérculos (Quadro 4).

Para o nível médio de produtividade de $40.000 \mathrm{~kg} \mathrm{ha}^{-1}$, obtido com as cultivares Mondial e Asterix (Fernandes et al., 2010), houve extração média por hectare de $71 \mathrm{~g}$ de B, $122 \mathrm{~g}$ de $\mathrm{Cu}, 2.228 \mathrm{~g}$ de Fe, $618 \mathrm{~g}$ de Mn e $405 \mathrm{~g}$ de Zn (Figuras 2f, 3f, 4f, 5f e $6 \mathrm{f} \mathrm{e}$ Quadro 2), bem como a exportação de aproximadamente $39 \mathrm{~g}$ de B, $63 \mathrm{~g}$ de $\mathrm{Cu}, 273 \mathrm{~g}$ de Fe, 53 g de Mn e 139 g de Zn (Quadro 4). Já para o menor nível de produtividade $\left(22.544 \mathrm{~kg} \mathrm{ha}^{-1}\right.$ da cultivar Atlantic), foram absorvidos 50, 81, 1.960, 544 e $270 \mathrm{~g} \mathrm{ha}^{-1}$ de $\mathrm{B}, \mathrm{Cu}, \mathrm{Fe}, \mathrm{Mn}$ e $\mathrm{Zn}$, respectivamente, com exportação por hectare de $22 \mathrm{~g}$ de B, $16 \mathrm{~g}$ de $\mathrm{Cu}$, $241 \mathrm{~g}$ de $\mathrm{Fe}, 37 \mathrm{~g}$ de $\mathrm{Mn}$ e $83 \mathrm{~g}$ de Zn (Figuras 2f, 3f, 4f, $5 \mathrm{f}$ e $6 \mathrm{f}$ e Quadros 2 e 4).

De modo geral, aproximadamente $60 \%$ do total de B extraído pelas cultivares de batata foi exportado pelos tubérculos. Os nutrientes $\mathrm{Cu}$ e $\mathrm{Zn}$ apresentaram valores intermediários, com exportação de $43 \%(\mathrm{Cu})$ e $35 \%$ (Zn) da extração total. As menores proporções foram observadas para os micronutrientes Fe e Mn, com valores em torno de 13 e $10 \%$, respectivamente. No entanto, a ordem de exportação de micronutrientes pelas cultivares de batata foi a seguinte: $\mathrm{Fe}>\mathrm{Zn}>$ $\mathrm{Mn}>\mathrm{B}>\mathrm{Cu}$. Nas cultivares Markies e Mondial, o $\mathrm{Cu}$ foi mais exportado que o B (Quadro 4). 


\section{CONCLUSÕES}

1. As cultivares Mondial e Asterix, mais produtivas, apresentaram maior extração de micronutrientes, com quantidades médias por hectare de $71 \mathrm{~g}$ de $\mathrm{B}$, 122 g de Cu, 2.228 g de Fe, 618 g de Mn e 405 g de Zn. As menores quantidades absorvidas foram observadas na cultivar Atlantic, com valores de 50, 81, 1.960, 544 e $270 \mathrm{~g} \mathrm{ha}^{-1}$ de B, Cu, Fe, Mn e Zn, respectivamente.

2. A fase de maior demanda por B ocorre logo após o início da formação de tubérculos, aos 34 DAP, enquanto a maior exigência por $\mathrm{Fe}$ e $\mathrm{Mn}$ inicia-se a partir dos $42 \mathrm{DAP}$ e vai até $63 \mathrm{DAP}$. O Cu e o Zn são absorvidos em maiores proporções a partir dos 64 DAP até o final do ciclo.

3. A quantidade de B, Cu, Mn e Zn exportada foi dependente da cultivar utilizada, com valores por hectare variando de 48 a $22 \mathrm{~g}$ de B, 79 a $16 \mathrm{~g}$ de $\mathrm{Cu}$, 65 a 37 g de $\mathrm{Mn}$ e 167 a 83 g de $\mathrm{Zn}$. A quantidade de Fe exportada não variou entre as cultivares, sendo, em média, de $243 \mathrm{~g} \mathrm{ha}^{-1}$.

4. A quantidade de micronutrientes extraída e exportada pela batateira variou entre as cultivares utilizadas, indicando necessidade de manejo diferencial da adubação.

\section{AGRADECIMENTOS}

Ao Grupo Ioshida, pela concessão da área para condução do experimento. À Associação Brasileira da Batata (ABBA), pelo auxílio financeiro. Ao CNPq, pela concessão de bolsa de Mestrado ao segundo autor.

\section{LITERATURA CITADA}

ASSOCIAÇÃO BRASILEIRA DA BATATA - ABBA. Variedades. R. Batata Show, 10:1-4, 2010.

BERTSCH, F. La fertilidad de los suelos y su manejo. San José, Costa Rica, ACCS, 1998. 157p.

BOOCK, O.J. Os micronutrientes na cultura da batata. In: AGIPLAN-MA, ed. Tecnologia e produção de batatassemente. Brasília, Ministério da Agricultura, 1976. p.81. 96.

CABALCETA, G.; SALDIAS, M. \& ALVARADO, A. Absorción de nutrientes en el cultivar de papa MNF-80. Agron. Costarricense, 29:107-123, 2005.

CARDOSO, A.D.; ALVARENGA, M.A.R.; MELO, T.L. \& VIANA, A.E.S. Produtividade e qualidade de tubérculos de batata em função de doses e parcelamentos de nitrogênio e potássio. Ci. Agrotec., 31:1729-1736, 2007.

COGO, C.M.; ANDRIOLO, J.L.; BISOGNIN, D.A.; GODOI, R.S.; BORTOLOTTO, O.C. \& LUZ, G.L. Relação potássionitrogênio para o diagnóstico e manejo nutricional da cultura da batata. Pesq. Agropec. Bras., 41:1781-1786, 2006.
DECHEN, A.R. \& NACHTIGALL, G.R. Micronutrientes. In: FERNANDES, M.S., ed. Nutrição mineral de plantas. Viçosa, MG, Sociedade Brasileira de Ciência do Solo, 2006. p.328-352.

EMPRESA BRASILEIRA DE PESQUISA AGROPECUÁRIA EMBRAPA. Sistema brasileiro de classificação de solos. 2.ed. Rio de Janeiro, Embrapa Solos, 2006. 306p.

FAOSTAT - Food and Agriculture Organization of the United Nations. Yield - Potatoes. Disponível em: <http:// faostat.fao.org/site/567/DesktopDefault.aspx? PageID=567>. Acesso em: 06 abr. de 2011.

FERNANDES, A.M.; SORATTO, R.P.; SILVA, B.L. \& SOUZASCHLICK, G.D. Crescimento, acúmulo e distribuição de matéria seca em cultivares de batata na safra de inverno. Pesq. Agropec. Bras., 45:826-835, 2010.

FILGUEIRA, F.A.R. Nutrição mineral e adubação em bataticultura, no Centro-Sul. In: FERREIRA, M.E.; CASTELLANE, P.D. \& CRUZ, M.C.P. Nutrição mineral e adubação de hortaliças. Piracicaba, Potafós, 1993. p.401428.

FREIRE, F.M.; MARTINS, FILHO, C.A. \& MONNERAT, P.H. Nutrição mineral e adubação da batata. Inf. Agropec., 7:24-30, 1981.

GARGANTINI, H.; LEITE, N. \& HUNGRIA, L.A. Aplicação de micronutrientes em cultura da batata, em solos de várzea. Hortic. Bras., 4:50, 1986.

GARGANTINI, H.; LEITE, N.; HUNGRIA, L.S. \& VENTURINI, W.R. Efeito de micronutrientes na produção e no tipo de tubérculos de batata, em cultura efetuada em solos de várzea do Vale do Paraíba. Bragantia, 29:1-10, 1970.

GREEF, J.M.; OTT, H.; WULFES, R. \& TAUBE, F. Growth analysis of dry matter accumulation and $\mathrm{N}$ uptake of forage maize cultivars affected by N supply. J. Agric. Sci., 132:31-43, 1999.

JONES JUNIOR, J.B.; WOLF, B. \& MILL, H.A. Plant analysis handbook. Geórgia, Micro-Macro Publishing, 1991. 213p.

LORENZI, J.O.; MONTEIRO, P.A.; MIRANDA FILHO, H.S. \& RAIJ, B.van. Raízes e tubérculos. In: RAIJ, B.van.; CANTARELLA, H.; QUAGGIO, J.A. \& FURLANI, A.M.C., eds. Recomendações de adubação e calagem para o Estado de São Paulo. Campinas, Instituto Agronômico de Campinas, 1997. p.221-229. (Boletim Técnico, 100)

MALAVOLTA, E. Manual de nutrição mineral de plantas. São Paulo, Agronômica Ceres, 2006. 638p.

MALAVOLTA, E.; VITTI, G.C. \& OLIVEIRA, S.A. Avaliação do estado nutricional de plantas: Princípios e aplicações. 2.ed. Piracicaba, Potafós, 1997. 308p.

MARSCHNER, H. Mineral nutrition of higher plants. 2.ed. London, Academic Press, 1995. 889p.

MESQUITA FILHO, M.V.; SOUZA, A.F. \& FURLANI, P.R. Hortaliças de bulbo, tubérculo, raíz e fruto. In: FERREIRA, M.E.; CRUZ, M.C.P.; RAIJ, B.van. \& ABREU, C.A., eds. Micronutrientes e elementos tóxicos na agricultura. Jaboticabal, CNPQ/FAPESP/POTAFOS, 2001. p.511-525. 
MESQUiTA, H.A.; ALVARENGA, M.A.R.; PAULA, M.B.; CARVALHO, J.G. \& NÓBREGA, J.C.A. Teores de nutrientes na parte aérea da batateira em resposta ao boro. Ci. Agrotec., 32:1872-1878, 2008.

MESQUiTA, H.A.; ALVARENGA, M.A.R.; PAULA, M.B.; CARVALHO, J.G. \& NÓBREGA, J.C.A. Produção e qualidade da batata em resposta ao boro. Ci. Agrotec., 31:385-392, 2007.

ORLANDO FILHO, J.; ROSSETTO, R. \& CASAGRANDE, A.A. Cana-de-açúcar. In: FERREIRA, M.E.; CRUZ, M.C.P.; RAIJ, B.van. \& ABREU, C.A., eds. Micronutrientes e elementos tóxicos na agricultura. Jaboticabal, CNPQ/ FAPESP/POTAFOS, 2001. p.355-369.

PAULA, M.B.; FONTES, P.C.R. \& NOGUEIRA, F.D. Absorção de micronutrientes por cultivares de batata em presença e ausência de adubação. Hortic. Bras., 4:3-7, 1986.

RAIJ, B.van. Pesquisa e desenvolvimento em micronutrientes e metais pesados. In: FERREIRA, M.E.; CRUZ, M.C.P.; RAIJ, B.van. \& ABREU, C.A., eds. Micronutrientes e elementos tóxicos na agricultura. Jaboticabal, CNPQ/ FAPESP/POTAFOS, 2001. p.1-11.

RAIJ, B.van; ANDRADE, J.C.; CANTARELLA, H. \& QUAGGIO, J.A. Análise química para avaliação da fertilidade de solos tropicais. Campinas, Instituto Agronômico de Campinas, 2001. 284p.
RAIJ, B.van; QUAGGIO, J.A.; CANTARELLA, H. \& ABREU, C.A. Interpretação de resultados de análise de solo. In: RAIJ, B.van; CANTARELLA, H.; QUAGGIO, J.A. \& FURLANI, A.M.C., eds. Recomendações de adubação e calagem para o Estado de São Paulo. Campinas, Instituto Agronômico de Campinas, 1997. p.8-13. (Boletim Técnico, 100)

RAVEN, J.A. Short and long distance transport of boric acid in plants. New Physiol., 84:231-249, 1980.

SILVA, T.O.; MENEZES, R.S.C.; TIESSEN, H.; SAMPAIO, E.V.S.B.; SALCEDO, I.H. \& SILVEIRA, L.M. Adubação orgânica da batata com esterco e, ou, Crotalaria juncea. I - Produtividade vegetal e estoque de nutrientes no solo em longo prazo. R. Bras. Ci. Solo, 31:39-49, 2007.

STRUIK, P.C.; VREUGDENHIL, D.; van ECK, H.J.; BACHEM, C.W. \& VISSER, R.G.F. Physiological and genetic control of tuber formation. Potato Res., 42:313-331, 1999.

TAIZ, L. \& ZEIGER, E. Fisiologia vegetal. 3.ed. Porto Alegre, Artmed, 2004. 559p.

YORINORI, G.T. Curva de crescimento e acúmulo de nutrientes pela cultura da batata cv. 'Atlantic'. Piracicaba, Escola Superior de Agricultura Luiz de Queiroz, 2003. 66p. (Tese de Mestrado) 
